\title{
Space Operation of the MOLA laser
}

\author{
Robert S. Afzal \\ NASA-GSFC
Space
5004 College Ave.
College Park, MD 20740
(301) 403-8360 (V) - 4642 (F) \\ E-mail: Robert.Afzal@gsfc.nasa.gov
}

\begin{abstract}
The MOLA laser has been in Space almost 3 years and began continuous operation, collecting topographic data of Mars, over 7 months ago. The in-space performance of the laser is presented.
\end{abstract}




\title{
Space Operation of the MOLA laser
}

\author{
Robert S. Afzal \\ NASA-GSFC \\ Space Lidar Technology Center \\ 5004 College Ave. \\ College Park, MD 20740 \\ (301) 403-8360 (V) - 4642(F) \\ E-mail: robert.afzal@gsfc.nasa.gov
}

\section{Introduction}

Interest in lasers for space applications such as active remote sensing in Earth orbit, planetary science, and inter-satellite laser communications is growing. These instruments typically use diodepumped solid state lasers for the laser transmitter. The mission specifications and constraints of space qualification, place strict requirements on the design and operation of the laser. Although a laser can be built in the laboratory to meet performance specifications relatively routinely, the mission constraints demand unique options and compromises in the materials used, and design to ensure the success of the mission. Presently, the best laser architecture for a light weight, rugged, high peak power and efficient transmitter is a diode laser pumped Nd:YAG laser. Diode lasers can often obviate the need for water cooling, reduce the size and weight of the laser, increase the electrical to optical efficiency, system reliability, and lifetime. This paper describes the in-space operation and performance of the Mars Orbiter Laser Altimeter (MOLA) laser transmitter', representing the current state-of-the-art in space-based solidstate lasers.

\section{Mars Orbiter Laser Altimeter: Laser Transmitter}

On November 5, 1996, NASA launched the Mars Global Surveyor (MGS). MGS is intended to recover as much of the science data possible from the earlier loss of the Mars Observer spacecraft. One of the science instruments on MGS is the Mars Orbiter Laser Altimeter (MOLA). MOLA's primary mission is to gather Martian topographic data on a $0.2^{\circ} \times 0.2^{\circ}$ grid with $30 \mathrm{~m}$ vertical accuracy and short baseline $(\approx 100 \mathrm{~km})$ topographic profiles with a $<2 \mathrm{~m}$ vertical accuracy ${ }^{2}$. The MOLA laser transmitter utilizes a diode-laser pumped Nd:YAG laser which when a previous version was flown on ill-fated Mars Observer, was the first diode-laser pumped solid state laser to operate in space. The laser was designed and built by Boeing (McDonnell-Douglas Aerospace), St. Louis, MO, with the diode pump arrays provided as government furnished equipment. A photograph of the laser is shown in figure 1 .

The MOLA laser transmitter is required to deliver $>25 \mathrm{~mJ}$ pulses at $10 \mathrm{~Hz}$, through 0.6 billion shots $(\approx 2$ Earth years -1 Martian year). The laser weighs $<5.5 \mathrm{Kg}$ and is $3.3 \%$ efficient from $28 \mathrm{~V}$ prime power to light out. Some of the environmental conditions that the instrument must survive uncompromised are, launch vibrations both random and sinusoidal, pyrotechnic shock and launch sound levels. The instrument capabilities must not be degraded under the conditions of thermal cycling ( between 0 and $40^{\circ} \mathrm{C}$ ) and must withstand radiation dosages expected during the mission For this mission not only does the laser transmitter (LT) need to survive launch and the journey to Mars, but had to meet the specifications summarized in Table 1 .

\begin{tabular}{lcccccc} 
Parameter & Weight $(\mathrm{Kg})$ & $\begin{array}{c}\text { Available } \\
\text { Power }\end{array}$ & $\begin{array}{c}\text { Table 1 } \\
\text { Pulse } \\
\text { Energy }\end{array}$ & $\begin{array}{c}\text { Pulse } \\
\text { Width }\end{array}$ & $\begin{array}{c}\text { Repetition } \\
\text { Rate }\end{array}$ & $\begin{array}{c}\text { Lifetime } \\
\text { (shots) }\end{array}$ \\
\cline { 2 - 4 } & & $(\mathrm{W})$ & $(\mathrm{mJ})$ & $(\mathrm{nS})$ & $(\mathrm{Hz})$ & \\
Specifications & 6.26 & 15 & 40 & 10 & 10 & $6 \times 10^{8}$ \\
Actual & 5.38 & 14.7 & 49 & 8.4 & 10 & TBD
\end{tabular}

The MOLA laser design is a side-pumped zig-zag slab, crossed porro resonator, power oscillator. The laser optics, diode arrays, power and control electronics are housed in an all beryllium enclosure which was used to mate and match the $0.5 \mathrm{~m}$ beryllium receiver telescope. After assembly and vacuum testing at 
Boeing (McDonnell-Douglas) the laser cavity was kept sealed and only vented with a burst disc after launch to maintain cleanliness. The MOLA laser is radiation tolerant, designed to operate in both the air and vacuum environment, with great care and effort expended to make the laser vacuum compatible.

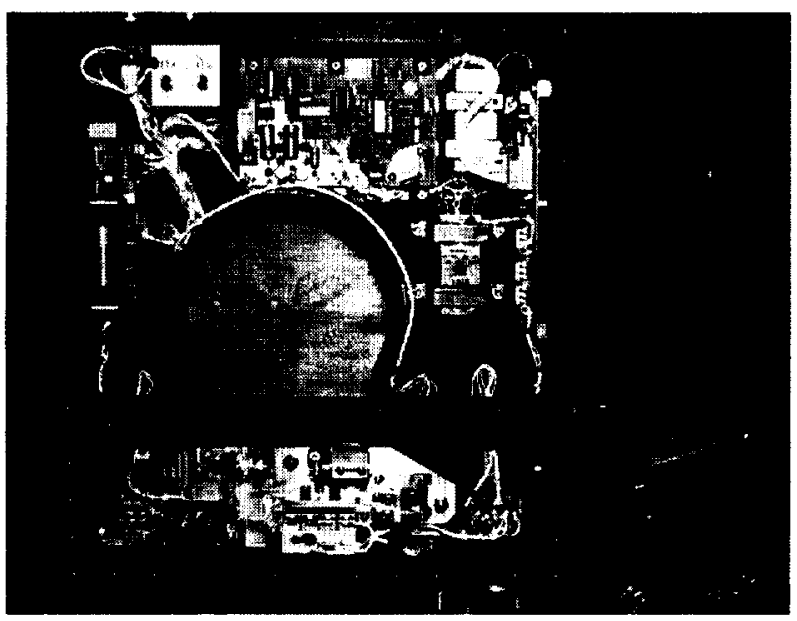

FIGURE 1 - Photograph of the MOLA laser transmitter with covers off. For scale, the main box is about $30 \mathrm{~cm} \times 30 \mathrm{~cm}$ in size.

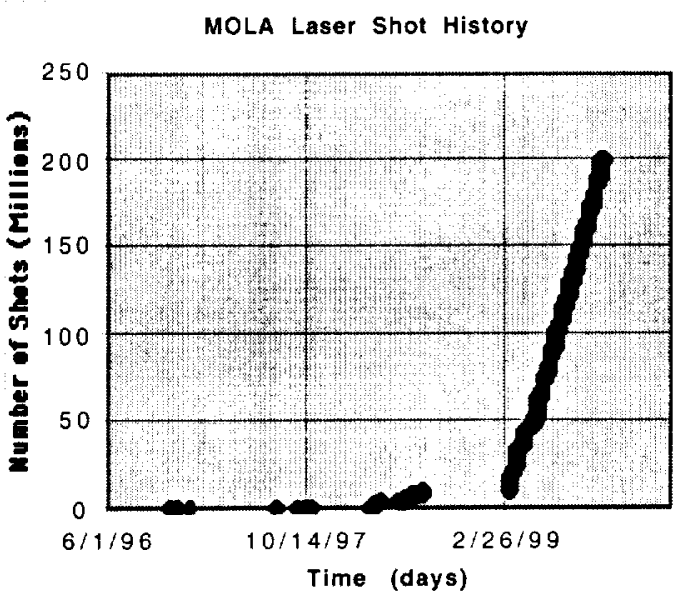

FIGURE 2 - Laser shot history from launch continuing through $10 / 15 / 99$. At the time of press the laser is still operating.

The MOLA instrument went "operational" on 2/28/99 and continues to collect topography data 24 hrs/day, 7 days a week. At $10 \mathrm{~Hz}$, the laser accumulates about 866,000 shots per day, and has emitted over 200 million shots to date. After launch in $11 / 96$, the laser was operated 4 times for checkouts during the 10 month cruise to Mars. After an anomaly was discovered in the solar array structure, aerobraking activities were ceased and interim science data gathering activities were planned and executed gathering data before the conclusion of aerobraking. ${ }^{3}$. These so called Science Phasing Orbits (SPO) were unplanned, and the laser was not designed or tested for this condition. Never the less the laser performed as expected and endured hundreds of off-on power cycles. Since launch, the laser (and Instrument) has been power cycled 214 times with no sign of degradation. Figure 2 shows the shot history of the laser starting from launch through system checkouts, SPO's and finally continuous operation.

The MOLA laser is all conductively cooled with no active temperature control of the laser or laser pump arrays. Therefor the laser was designed to operate over a wide temperature range and still meet energy performance margins. This was accomplished by distributing the diode array wavelength over the $\mathrm{Nd}: \mathrm{YAG}$ absorption band. As the heat sink temperature changed, different portions of the pump array were matched to the absorption peak. The laser and can operate over $30^{\circ} \mathrm{C}$ while providing $>80 \%$ of its peak energy which is achieved when the diode array heat sink is at $\approx 31^{\circ} \mathrm{C}$. Figure 3 shows the laser energy and array heat sink temperature as a function of shot number. The first 10 million shots represent data taken through cruise and science phasing orbits. From 10 million to about 35 million shots the laser was operated continuously but with the spacecraft high-gain antenna not deployed, the spacecraft was pointed toward Earth once per orbit to communicate. The temperature variations caused by this slewing can be observed in the data. From about 35 million shots on, with the high gain antenna deployed, and the laser energy and temperature data is stable allowing for trending observations. The laser energy has exhibited some near discreet drops in energy, which is hypothesized to be evidence of possible shunting in the diode arrays. Due to the lack of telemetry however, this is speculation. Regardless, the laser energy still far exceeds the link requirement ${ }^{4}$ and has been extremely successful in allowing the MOLA instrument to obtain truly revolutionary information about the planet Mars ${ }^{5,6}$.

\section{Conclusions}

At the time of this submission, the MOLA laser has been in the vacuum of Space for almost 3 years, has been turned off and on over 214 times, emitted over 190 million pulses, and been in a radiation environment of about $30 \mathrm{krads}$. The laser is still in excellent health and continues to collect important data 
about the planet Mars. MOLA is an example that diode-pumped solid-state lasers have the promise for long term operational use in space for active remote sensing and other applications.

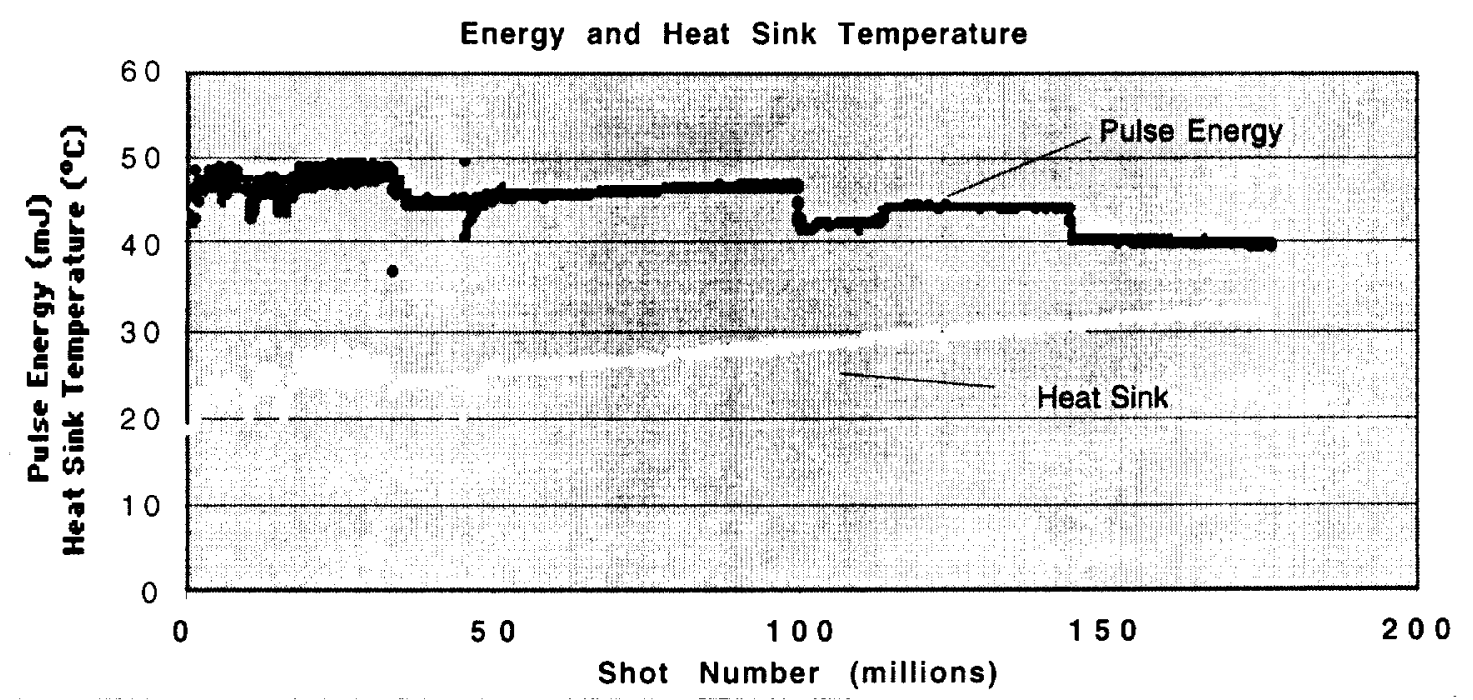

Figure 3 - Laser pulse energy and diode array heat sink temperature as a function of shot number. The laser is designed for peak energy with the array heat sink temperature at $31{ }^{\circ} \mathrm{C}$.

\section{Acknowledgments}

The author thanks the MOLA team at Boeing (McDonnell-Douglas) for their hard work and perseverance in building the transmitter, the MOLA Instrument and Science team for continued excellent data and Jeff Schott for reducing these data files.

\section{References}

1) Afzal, R. S., (1994), "Mars Observer Laser Altimeter: Laser Transmitter," Applied Optics, Vol. 33, No. 15, p. 3184, 20 May, 1994.

2) Zuber, M. T., D. E. Smith, S. C. Solomon, D. O. Muhlman, J. W. Head, J. B. Garvin, J. B. Abshire, and J. L. Bufton; (1992) "The Mars Observer Laser Altimeter Investigation", J. Geophys. Res., Vol. 97, E5, pp 7781-7797, May 25, 1992.

3) Smith, D.E., M.T. Zuber, H.V. Frey, J.B. Garvin, J.W. Head, D.O. Muhleman, G.H. Pettengill, R.J. Phillips, S.C. Solomon, H.J. Zwally, W.B. Banerdt, T.C. Duxbury, "Topography of the Northern Hemisphere of Mars from the Mars Orbiter Laser Altimeter”, Science, 279, pp. 1686-1692, 1998.

4) Abshire, J.B., X. Sun and R.S. Afzal, "Mars Orbiter Laser Altimeter: Receiver model and performance analysis", Appl. Optics, in press, 1999.

5) Zuber, M.T., Smith, D.E., S.C. Solomon, J.B. Abshire, R.S. Afzal, O. Aharonson, K. Fishbaugh, P.G. Ford, H.V. Frey, J.B. Garvin, J.W. Head, A.B. Ivanov, C.L. Johnson, D.O. Muhleman, G.A. Neumann, G.H. Pettengill, R.J. Phillips, X. Sun, H.J. Zwally, W.B. Banerdt, T.C. Duxbury, "Observations of the North Polar Region of Mars from the Mars Orbiter Laser Altimeter", Science, 282, pp. 2053-2060, 1998.

6) Smith, D.E., M.T. Zuber, S.C. Solomon, R.J. Phillips, J.W. Head, J.B. Garvin, W.B. Banerdt, D.O. Muhleman, G.H. Pettengill, G.A. Neumann, F.G. Lemoine, J.B. Abshire, O. Aharonson, C.D. Brown, S.A. Hauck, A.B. Ivanov, P.J. McGovern, H.J. Zwally, T.C. Duxbury, "The Global Topography of Mars and Implications for Surface Evolution", Science, 284 1495-1503, 1999. 
Robert S. Afzal

NASA/Goddard Space Flight Ctr.

Space Lidar Tech. Center

5004 College Avenue

College Park, MD 20740-0000

United States

Dear Dr. Afzal:

On behalf of the Technical Program Committee, we are pleased to advise you that your paper has been accepted for oral presentation at the Advanced Solid-State Lasers Topical Meeting. The meeting will be held February 13-16, 2000, at the Davos Congress Center in Davos, Switzerland. Each presentation is allotted 15 minutes; 12 minutes for presenting your paper, and 3 minutes for discussion. The first letter indicates the day of the week $(M=M o n d a y, T u=T u e s d a y$ and $\mathrm{W}=\mathrm{Wednesday)}$ for your presentation.

Article Title: Space operation of the MOLA laser, Session Code: WE1

Session Title: One Micron Lasers

Begin and end times: February 16, 2000 2:00pm - 2:15pm

Room: Theatersaal

May we call your attention to the audiovisual equipment available in the meeting room as outlined on the enclosed sheet. Please note that if you need equipment other than what is provided in the meeting room, you must order and pay for it directly from the conference audiovisual company in advance.

Because you are the corresponding author, we are addressing this notification to you. Please make sure any additional author's associated with your paper are also notified of this presentation.

Enclosed are preregistration and hotel accommodation forms. Please note that the Hotel Reservation Deadline is December 15, 1999. It is high season for travel in Switzerland so I encourage you to make your travel arrangements as soon as possible. A copy of the Advance Program will be sent to you as soon as it becomes available.

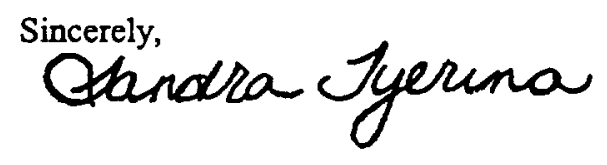

Sandra Tijerina

Technical Publications Editor
Optical Society of America 2010 Massachusetts Ave. NW Washington, DC 20036-1023 Tel 202/223-8130

Fax 202/223-1096 